\title{
A CONCILIAÇÃO E MEDIAÇÃO NO DIREITO PREVIDENCIÁRIO
}

\section{ARTIGO ORIGINAL}

FREITAS, Neusa Aparecida de Morais ${ }^{1}$

SANTOS, Lucineia Rosa Dos ${ }^{2}$

REIS, Elisa Da Penha De Melo Romano ${ }^{3}$

${ }^{1}$ Mestranda em Direito Previdenciário pela Pontifica Universidade Católica de São Paulo - PUC-SP. - Pós-Graduada em Direito e Processo do Trabalho pela Universidade Presbiteriana Mackenzie, e Graduada em Direito pela Universidade Padre Anchieta - UniAnchieta/Jundiaí-SP.

2 Doutora em Direitos Humanos pela mencionada Universidade. Mestre em Direito do Trabalho pela PUC/SP e Bacharel em Direito pela Pontifícia Universidade Católica de São Paulo. Professora na Pontifícia Universidade Católica nas áreas de Direitos Humanos, Direitos Humanos dos Refugiados e no Direito da Criança e do Adolescente e na disciplina Direito de Igualdade Gênero - Racial. Advogada Militante nas áreas do Direito do Trabalho, Direito Previdenciário e no Terceiro Setor.

${ }^{3}$ Mestranda em Direito Processual Civil pela Pontifica Universidade Católica de São Paulo - PUC-SP. - Especialização em Direito Processual Civil pela Pontifica Universidade Católica de São Paulo - PUC-SP, Mediadora certificada pelo Tribunal de Justiça de São Paulo, Professora e Coordenadora do Estagio Supervisionado do Curso de Direito do Centro Universitário Salesiano de São Paulo - UNISAL 2005/2011, Professora orientadora do estágio supervisionado da Universidade Cruzeiro do Sul - UNICSUL 2000/2003, Presidente da Comissão OAB vai a Faculdade da 125 Subseção Santana - Ordem dos Advogados de São Paulo - 2012/2021, Defensora do $5^{\circ}$ Tribunal de Ética da Ordem dos Advogados do Brasil - Seccional de São Paulo, Graduada em Direito pela Faculdade Metropolitana Unida - FMU/SP-199. 
GONÇALVES, lonas Deda ${ }^{4}$

FREITAS, Neusa Aparecida de Morais. Et al. A conciliação e mediação no Direito Previdenciário. Revista Científica Multidisciplinar Núcleo do Conhecimento. Ano 05, Ed. 12, Vol. 18, pp. 05-21. Dezembro de 2020. ISSN: 2448-0959, Link de acesso: https://www.nucleodoconhecimento.com.br/lei/direito-previdenciario

\section{RESUMO}

O presente artigo objetiva estudar as formas de concretização da providência jurisdicional, pela ótica dos procedimentos de mediação atrelados aos procedimentos do processo civil e previdenciário. Analisar-se-á a efetividade dos métodos de soluções de conflitos consensuais no Campo do Direito Previdenciário, tendo como suporte a dogmática do fenômeno jurídico processual, a partir dos ditames constitucionais e dos princípios norteadores da Lei de Mediação, e com especial preocupação no novo cenário infraconstitucional trazido com a edição do CPC de 2015.

Palavras-chaves: Conciliação, mediação, Lei 13.140/2015, Lei 12.154/2009, Ações Previdenciárias.

\section{INTRODUÇÃO}

É de fundamental importância para o sistema processual a conciliação e a mediação, sendo atividades jurisdicionais e meios alternativos de solução de litígio, utilizados de forma menos desgastante para as partes.

Sendo meios alternativos utilizados para desafogar os órgãos judiciais e considerado como instrumento adequado para a efetivação do princípio da razoável duração do processo, com medidas que contribui para maior celeridade processual.

\footnotetext{
${ }^{4}$ Orientador. Doutorado em Direito. Mestrado em Direito.
} 
Com destaques nos novos diplomas legais, os quais disciplinam o tema como a Lei no 13.105/2015 (novo Código de Processo Civil) e a Lei oㅜ 13.140/2015 (Lei da Mediação), visando reduzir a judicialização dos conflitos, em consonância com o Poder Judiciário.

Tendo como um tópico fundamental, o qual se destina à identificação das principais normas processuais sobre conciliação e mediação trazidas pelo Novo CPC e pela Lei de Mediação que pode impactar a prática consensual nas ações previdenciárias.

Tendo-se a necessidade de garantir os preceitos fundamentais e constitucionais do processo, simultaneamente ao devido processo legal, que exige sua forma justa, pautados na colaboração dos atores do processo e da ponderação normativa, analisando o caso concreto, em busca da justiça.

\section{IMPACTO DA CONCILIAÇÃO E MEDIAÇÃO NAS AÇÕES PREVIDENCIÁRIAS}

O impacto da conciliação e mediação nas Ações Previdenciárias tem sido um grande marco no âmbito judiciário, sendo a princípio baseada num meio de garantia do direito à seguridade social do segurado. Tendo ainda seu meio conciliatório como meio consensual de solução dos conflitos perante a sua vasta demanda processual a qual colabora com a grande demanda processual e na diminuição da morosidade processual com a proteção aos princípios constitucionais. Conseguindo assim, solucionar maiores números de processos, com mais agilidade e eficácia perante o poder judiciário.

Com a grande demanda dos processos judiciais, a aplicação da medida de audiências com conciliadores e mediadores foi um grande aperfeiçoamento nas relações humanas e na cidadania, a qual mostrou ser um grande marco no acesso à justiça, vindo ainda a se alavancar cada vez mais com vários ajuizamentos em milhões de ações. 
Com o avanço das audiências efetuadas por conciliadores e mediadores, temos um grande número de acordos celebrados entre as partes em conflitos, os quais demonstram que a conciliação, de certa forma, acaba aproximando os cidadãos em conflito, envolvendo todos os tipos de cidadãos, empresas e instituições diversas, fazendo com que cada parte se componha e entenda a importância da parte contrária, e ainda entenda o papel do agente reivindicante de transformações e de fiscalização do bem público, social e coletivo.

Nos casos das ações previdenciárias, a conciliação vem se estendendo cada dia mais, sendo uma prática já sedimentada, principalmente nas causas submetidas aos Juizados Especiais Federais, que é um órgão absolutamente competente para julgar as causas de competência da Justiça Federal de valores de até 60 (sessenta) saláriosmínimos.

Neste sentido, temos que a conciliação e a mediação vêm sendo trazidas pelo Novo CPC e pela Lei de Mediação, a qual é de fundamental importância para as normas processuais que vieram para impactar a prática consensual nas diversas ações judiciais, sendo também aplicadas nas ações previdenciárias.

Através do conjunto de conhecimentos desenvolvidos no campo do estudo da mediação, observou-se uma influência positiva sobre a conciliação judicial, o que também favoreceu totalmente o aprimoramento dessa prática, com a eficácia do sistema judiciário e a efetividade dos direitos previdenciários, porém não correspondendo aos princípios constitucionais, ante as várias situações e dúvidas levantadas em relação às partes envolvidas.

Tendo como parte o Instituto Nacional do Seguro Social - INSS, o qual apresenta um quadro de diversas dúvidas pairando sobre as bases e critérios que são celebrados, uma vez que as audiências de conciliação previdenciárias discutem os direitos previdenciários que são direitos constitucionais.

Desta forma, existem vários entendimentos em relação à conciliação neste âmbito, como forma de desconstrução do direito previdenciário, uma vez que o acordo em sua 
grande maioria busca, de certa forma, reduzir gastos considerando a proposta da conciliação, o qual se trata de pagamento de menor valor, tentando em fase de conciliação limitar o valor devido ao limite do Juizado Especial Federal.

Comprovando que a parte autora estaria sendo, de certa forma, influenciada a conciliar e até mesmo a aceitar o acordo estipulado em audiência de conciliação, e por não ter as mesmas condições financeiras e econômicas para suportar o tempo do processo judicial, acaba sendo incentivada pela conciliação.

Desta forma, os estudos em relação aos acordos celebrados no âmbito das ações previdenciárias, os quais a parte autora acaba renunciando seus direitos previdenciários, deixando o Instituto Nacional de Seguro Social - INSS amparado nas vantagens que possui como litigante e na aceitação designada ao segurado que recebe o valor ofertado para não correr o risco da demora na demanda judicial, não suportando tal situação, que poderia onerar ainda mais sua espera pelo benefício pleiteado, aceitando assim a proposta em audiência de conciliação.

Nesta situação fica claro que o sistema da implantação das audiências de conciliação em ações previdenciárias, ainda é um método que deve ser analisado e estudado por ainda haver um descompasso entre 0 respeito aos direitos constitucionais previdenciários e o segurado. Sendo também necessário verificar se o método utilizado é realmente adequado à solução efetiva dessas demandas, devendo-se buscar uma análise profunda para não incorrer em equívocos, tão pouco privar os direitos constitucionais do segurado.

\section{DIFERENTES CAMPOS DE INCIDÊNCIA NO NOVO CPC, NA LEI}

\subsection{0/2015 E NA LEI 12.154/2009}

Quanto aos diferentes campos de incidência do CPC/2015 e da Lei ํo 13.140/2015, podemos dizer que os dois diplomas possuem campos de incidência diversos, enquanto o Novo CPC regula a mediação e a conciliação exercidas no âmbito judicial, sendo que a Lei de Mediação exclui a conciliação e regulamenta apenas a mediação nos âmbitos judicial e extrajudicial. 
Ambos os diplomas possuem técnicas de negociação previstas como instrumento para composição entre as partes, as quais foram devidamente reconhecidas. Sendo que os diplomas legais colaboram para disciplinar as audiências de conciliações e mediações, trazendo as partes um consenso, chegando a uma resolução do conflito com acordos celebrados entre as partes, no âmbito judicial ou extrajudicial.

De qualquer maneira, o CPC/2015 apresentou uma diferenciação normativa entre as duas palavras. A mediação aplica-se preferencialmente nos casos que apresentam vínculo prévio entre as partes, objetivando o restabelecimento da comunicação entre elas, de modo a lhes permitir, por si próprias, o alcance de soluções consensuais capazes de gerarem benefícios mútuos, enquanto a conciliação compreende, preferencialmente, os casos que não apresentam um vínculo prévio entre as pessoas, cabendo ao conciliador sugerir soluções para o litígio

E temos em relação ao mesmo tema a Lei № 13.140, de 26 de junho de 2015, que dispõe a mediação, em seu Artigo 1ํㅡ, como um meio de solução de conflitos entre particulares e no que diz respeito a autocomposição de controvérsias no âmbito da administração pública. No qual, ainda em seu Parágrafo único, considera a mediação como uma atividade técnica que é desempenhada por um terceiro imparcial sem poder decisório, o qual, sendo escolhido ou aceito pelas partes, tem como propósito auxiliar e estimular as mesmas na identificação e no desenvolvimento de soluções consensuais para a controvérsia (BRASIL, 2015).

Assim, em um sentido mais amplo, o sistema judiciário tornou-se mais imperativo em busca de um plano além do formal, buscando de outras maneiras a resolução de conflitos diversos, rompendo assim a visão tradicional de que a prestação jurisdicional só poderia ser dada pelo Juiz a partir da sentença, de um decreto imposto às partes, passando a ser defendidas de outras formas através da conciliação e mediação com o intuito de promover a cultura voltada à paz social, bem como também desafogar o escopo judicial.

Nos casos de soluções consensuais de conflito, existem várias vantagens, tanto para as partes, quanto para o sistema jurídico, os quais costumam ser mais rápidos e por 
ter sido acordado entre as partes, são cumpridas com maior eficácia do que aquelas impostas pelo Poder Judiciário. Temos também discussões refletindo na Resolução n. 125 , de 2010, do Conselho Nacional de Justiça - CNJ, a qual instituiu a Política Judiciária Nacional de tratamento adequado dos conflitos de interesse no âmbito do Poder Judiciário (BRASIL, 2010).

O conceito de acesso à Justiça não é mais tratado pela Resolução como mero acesso aos órgãos judiciários, passando a ser, portanto, considerado como um acesso à ordem jurídica justa. Ressaltando, deste modo, o direito dos jurisdicionados à solução dos conflitos de interesses que Ihes são apresentados, através dos meios mais adequados, segundo a sua natureza e a sua especificidade, permitindo-se a utilização da conciliação e da mediação, e, ademais, a disseminação da cultura voltada à paz social. Apresentando diretrizes para uma mudança paradigmática da solução de conflitos judiciais.

Sendo constatado que a conciliação possibilita vários tipos de abordagem, verifica-se que a mesma é a mais extensa em todos os aspectos e suas dimensões do litígio, conciliando os casos e relacionamentos mais prolongados e complexos, e proporcionando a possibilidade de restauração dos relacionamentos entre as partes através do estabelecimento do diálogo entre as mesmas para que cheguem a um entendimento, com a interveniência do conciliador.

Assim, em relação à autarquia federal temos que o Instituto Nacional de Seguro Social - INSS é responsável pela seguridade social, efetuando as conciliações com o intuito de transacionar e obter nos acordos o pagamento de valor menor do que aquele que o segurado teria direito ao fim do processo. Sendo a conciliação uma via desejável "quando o princípio da utilidade social preponderar, ou seja, onde o Estado entender ser melhor terminar a lide a seguir com seus custos, mesmo que dúvida haja sobre questão de fato ou de direito" (CABRAL, 2014).

Desta forma, temos que o princípio constitui o dever de buscar a conciliação quando possível e viável, enquanto o interesse público acredita ser mais importante a coletividade, uma autarquia ou órgão público. Dessa forma, a coletividade tem 
interesse no cumprimento dos princípios dispostos no texto constitucional, assim como não deve haver a vinculação das receitas da seguridade social às despesas de um processo que pode ser evitado ou reduzido.

\section{DO ARTIGO 334, CAPUT DO CPC - DA AUDIÊNCIA DE CONCILIAÇÃO OU DE MEDIAÇÃO}

A política da cultura da paz está insculpida no preâmbulo da constituição federal de 1988[5], na qual uma decisão justa é construída a partir do diálogo das partes para a solução pacífica das controvérsias.

É nesse quadro que a Resolução n. 125/2010 do Conselho Nacional de Justiça (CNJ), que dispôs sobre a "Política Judiciária Nacional de Tratamento Adequado dos Conflitos de Interesse no âmbito do Poder Judiciário" contribuiu, sobretudo, para um importante avanço na institucionalização da mediação e da conciliação, além da sistematização e do aprimoramento das práticas consensuais. A Resolução partiu da premissa de que os métodos consensuais são uma porta de acesso à Justiça integral.

Entre as inovações trazidas pelo CPC/2015, acolhem-se as soluções adotadas na conciliação e na mediação, que no essencial, corresponde ao estabelecido no artigo 6. - do CPC, o qual corresponde ao princípio da cooperação que permeia todo sistema processual civil, pela aplicação dos mecanismos de simplificação e estimulação do processual por parte do julgador, que garantam a justa composição do litígio em prazo razoável (BRASIL, 2015).

Um dos mecanismos para a solução do litígio, por via da conciliação ou de mediação, agora expressamente prevista pelo artigo 334, Caput do CPC, vem da premissa do que dispõe o artigo 27 e 46 da Lei 13.140/2015, sobre a mediação como meio de solução de conflitos para chegar à autocomposição no âmbito da administração pública.

Para José Maria Câmara Junior, o Novo Código antecipa a audiência preliminar para o momento que segue a admissibilidade da petição inicial, objetivando viabilizar a 
conciliação ou a mediação. A ratio legis quer permitir melhor gerenciamento, economicidade e efetividade da tutela jurisdicional a ser prestada.[6]

O ministro Marco Bruzzi é um entusiasta do mecanismo de solução de conflitos, como a conciliação e mediação, para ele, o acordo dá outro significado ao papel do Poder Judiciário e afasta a ideia segundo a qual para o conflito só pode haver uma solução correta: a do magistrado. Na autocomposição podem existir várias respostas corretas e legítimas para uma mesma questão, cabendo às partes construírem a solução. Crítica o argumento de que a audiência de conciliação ou mediação, exigida do novo CPC, pode ser dispensada pelo magistrado em prol da celeridade processual ou por falta de mediadores ou conciliadores. "Acho que isso vai repercutir gravíssimo risco de nulidade processual. Porque não se está cometendo só um equívoco, em que o resto do processo pode vir a sanar o erro. Não, está criando um procedimento que não está previsto no CPC"[7]

A solução das controvérsias encontra-se presente no nosso ordenamento jurídico em sua constitucionalidade. Em consequência, conciliação e/ou mediação é uma forma de solução de encerramento definitivo de litígio pelo acordo de vontade entre as partes envolvidas no conflito de interesses. Entendendo que a mediação pode ser empregada em qualquer controvérsia, judicial ou extrajudicial, diferenciando nesse ponto, os direitos disponíveis (art. $3^{\circ}$ da Lei 13.140/2015) em que as partes podem dispor e transacionar.

Esse entendimento é cabível em qualquer espécie de conflito, especialmente naqueles que outra parte é estatal.

A lei 13. 105/2015 abrange dispositivos sobre a mediação de conflitos judicializados ou não, e sobre a autocomposição de conflitos no âmbito da administração pública.

A lei de mediação estimula a autocomposição de conflitos envolvendo órgão da Administração Pública direta ou indireta, de todos os entes federados, sendo essas práticas indispensáveis à razoável duração dos processos e à redução dos altos custos da litigiosidade envolvendo entes públicos (VASCONCELOS, 2017). 
Estabelece no artigo 10: "Esta Lei dispõe sobre a mediação como meio de solução de controvérsias entre particulares e sobre a autocomposição de conflitos no âmbito da Administração Pública".

Extrai-se do CPC/2015, a perfeita harmonia com a lei de mediação (art. 32), estabelece no artigo 174:

A União, os Estados, o Distrito Federal e os Municípios criarão câmaras de mediação e conciliação, com as atribuições relacionadas à solução consensual de conflitos no âmbito administrativo, tais como:

I - Dirimir conflitos envolvendo órgãos e entidades da administração pública;

II- Avaliar a admissibilidade dos pedidos de resolução de conflitos, por meio de conciliação, no âmbito da administração pública;

III- promover, quando couber, a celebração de termo de ajustamento de conduta (BRASIL, 2015).

Continua o CPC/2015 no artigo 175: "As disposições desta Seção não excluem outras formas de conciliação e mediação extrajudiciais vinculadas a órgãos institucionais ou realizadas por intermédio de profissionais independentes, que poderão ser regulamentados por lei específica".

Na mesma linha, a Justiça Federal prestigia a audiência de conciliação e/ou mediação por meio da Resolução n. 397, que institui o Fórum Nacional Previdenciário e da Conciliação, criando ambiente propício para o debate interinstitucional, em âmbito nacional, entre o Judiciário e entidades ligadas à Previdência Social, como, entre outras, o Instituto Nacional do Seguro Social (INSS), a Advocacia-Geral da União (AGU) e a Defensoria Pública da União (DPU).[8]

É de se observar que os entes federativos são os grandes litigantes, e na outra ponta está o particular: o segurado que quer receber determinado benefício previdenciário ou o mutuário, que pretende revisar o seu financiamento da habitação (SFH - Sistema Financeiro da Habitação). 
Carlos Eduardo de Vasconcelos traz as lições de Ada Pellegrini Grinover, onde propõe o desenvolvimento de uma

"justiça conciliativa" no processo civil, segundo três princípios: o funcional, que visa o enfrentamento da inacessibilidade, da morosidade e do custo do Judiciário, de forma a exigir a implementação de uma política judiciária de mediação e conciliação; a função social, que consiste na pacificação social, a qual, geralmente, não é obtida pela sentença, que se limita a determinar, autoritariamente, a regra para o caso concreto, se resumindo sobre a solução da parcela de lide levada a juízo, sem a possibilidade de pacificar a lide sociológica; e o fundamento político, consistente na participação popular na administração da justiça, representada por ela, ao mesmo tempo, instrumento de controle, apresentando meio de intervenção popular direta pelos canais institucionais de conciliação e mediação (VASCONCELOS, 2017, p.85).

Que o alcance da paz social na solução dos conflitos de interesses pelos métodos da conciliação, mediação e na satisfação das expectativas atuais das partes, a pacificação das controvérsias não seja somente realizada pelo julgamento, no qual um perde e outro ganha; isso não significa dizer que não acredito na solução do litígio por um Juiz monocrático ou por um colegiado do Tribunal, mas em outras formas de solução de conflito mais dinâmicas e próximas das relações sociais, trazendo resultados expressivos na redução das demandas judiciais.

\section{DA OBRIGATORIEDADE, DA REALIZAÇÃO E DA AUDIÊNCIA CONSENSUAL}

A Lei de Mediação e o Código de Processo Civil, no que diz respeito aos meios consensuais de solução de disputas, exegeta do Código de Processo Civil, permitem que as partes façam a opção da audiência preliminar por consenso (art. 319, VII do CPC/2015), e a Lei de Mediação prevê como obrigatória a primeira reunião de mediação quando há cláusula de mediação pactuada pelas partes (art. $2^{\circ}, \S^{1^{\circ}}$ ). Qual lei deve prevalecer diante dessa divergência? 
A solução é dada pelo CPC/2015 no art. 1.045 CPC/2015: "§2. Permanecem em vigor as disposições especiais dos procedimentos regulados em outras leis, aos quais se aplicará supletivamente este código."

Para Bueno (2017):

Mas há alguma incompatibilidade entre poucas regras do novo CPC em comparação com as da Lei de Mediação, de modo que, quando entrarem em conflito, as desta última deverão prevalecer (por tratar de lei posterior, que revoga a anterior, e de lei específica que derroga a genérica). Apesar disso, pode-se falar hoje de um minissistema brasileiro de métodos consensuais de solução judicial de conflitos, formado pela Resolução n. $125 \mathrm{CNJ}$, pelo CPC e pela Lei de Mediação, naquilo em que não conflitarem.

Presume-se que os advogados, as partes e os que atuam em prol da justiça, passam efetivamente a responder pelo cumprimento do princípio da duração razoável do processo e da cooperação (art. $4^{\circ}$ e art. $6^{\circ}$ do $\mathrm{CPC}$ ), para a solução consensual do litígio, por meio dos requisitos da petição inicial (art. 319, VII do CPC) na realização da conciliação ou da mediação.

Art. 319, VII do CPC/2015 - a opção do autor pela realização ou não de audiência de conciliação ou mediação. "O réu não é mais citado para responder a ação, mas citado para comparecer a uma audiência de conciliação ou mediação, que admitir autocomposição"

§ 4º do art. 334 do CPC/2015 - A audiência não será realizada:

I - Se ambas as partes manifestarem, expressamente, desinteresse na composição consensual.

II - Quando não se admitir a autocomposição - causas complexas e indisponíveis que não admitam transação.

$\S 5^{\circ}$ - o autor indicará na petição inicial, seu desinteresse na autocomposição, e o réu deverá fazê-lo, por petição, apresentada com 10 dias de antecedência, contados da data da audiência.

A obrigatoriedade da realização da audiência consensual decorre da política constitucional, que na promulgação do CPC/2015, veio institucionalizar como meio de 
efetivar os meios adequados de soluções de controvérsias e o Tribunal Bandeirante vem decidindo nesse sentido, para dar concretude à norma processual. (TJSP, Agravo de Instrumento n. 2259490-76.2016.8.26.0000, Rel. Des. Campos Petroni, 27aㅗ Câmara de Direito Privado, j. 05.04.2017)

Agravo de instrumento. Decisão que aplicou multa às agravantes, em razão do não comparecimento à audiência de conciliação, nos termos do artigo 334, §8ำ do CPC. Insurgência. Inadmissibilidade. Expressa determinação legal para a imposição da multa, diante do não comparecimento injustificado à audiência de conciliação. Decisão mantida. Motivação da decisão que é adotada como razão de decidir em Segundo Grau. Aplicação do art. 252 do Regimento Interno deste Egrégio Tribunal de Justiça. Recurso não provido (MEDEIROS NETO, s.d).

Decorre das disposições das normas sobre o protagonismo das partes na solução de conflitos consensualmente (arts. 1ํ ao 6º 190 e 471), que estimula a conciliação e a mediação, tendo como apoio um terceiro imparcial, para a promoção dialogal entre as partes, possibilitando as ressignificações dos fatos ensejadores do conflito e desarmando os ânimos, para facilitar o entendimento nas soluções dadas por elas próprias.

O movimento da mediação permeia todo sistema processual civil, pode-se substituir o sistema beligerante, e, sim, facilitar o acesso à justiça e uma solução mais justa.

No ordenamento jurídico brasileiro, conforme se extrai do artigo $2^{\circ}$, §3ํㅡㄹ do CPC/2015, verifica-se a vontade do legislador: "A conciliação, a mediação e outros métodos de solução consensual de conflitos deverão ser estimulados por juízes, advogados, defensores públicos e membros do ministério público, inclusive no curso do processo judicial” (BRASIL, 2015).

É notório que uma sentença não pacifica as partes. O Estado-Juiz exara uma decisão que deságua, muitas vezes, em processo de execução com medidas coercitivas na busca de bens para o cumprimento da sentença, o que leva a perpetuar ainda mais o conflito. 
A sociedade é altamente litigante, e esse foi o meio mais utilizado para as soluções dos conflitos, tanto que a natureza de lide na concepção mais clássica (Carnelutti) corresponde a um conflito de interesses qualificado por uma pretensão resistida. Trata-se do núcleo essencial de um processo judicial civil, o qual visa resolver o conflito apresentado perante o juízo.

Importa salientar que o conflito está nas relações humanas, e as partes ao ingressarem com uma ação judicial agravam ainda mais a situação, o que pode levar a uma escalada do conflito e uma degradação das relações interpessoais, mas se os advogados têm os mecanismos da mediação no processo, tem a chave da pacificação dos conflitos. Não se concebe o bem estar da cidadania entre as pessoas se não existir o estado de paz. E a paz está vinculada na cultura, que vem sendo construída pelos advogados, conciliadores, mediadores e pelo Juiz.

Rui Barbosa já advertia, na oração dos moços, que "justiça atrasada não é justiça, senão clamorosa injustiça".

A demora judicial, a morosidade da justiça e a eternização das demandas são expressões, aparentemente pejorativas, utilizadas frequentemente para demonstrar a insatisfação generalizada com a lentidão da prestação jurisdicional. "Já foram postas mais benignas ou menos negativas para defini-las: ritmo do litígio no tempo ou tempo do processamento de uma causa". (DELGADO, 2003, p. 65)

É uma mudança de paradigma e Cássio leciona que

É uma tarefa árdua de todos os operadores do direito estimularem o uso dos métodos alternativos de solução de conflito, com especial atenção aos meios consensuais. As diversas normas introduzidas no CPC/2015, dentre as quais a audiência inicial de mediação e conciliação (art. 304), somada à edição da Lei n. 13.140/2015 tem o condão de alterar a realidade atual que cultua a sentença, para acolher os meios consensuais. Todavia, a mudança depende do esforço e vontade de todos aqueles que operam o direito para efetivar o conteúdo da lei (BUENO, 2017, p.87).

Nesse sentido, os métodos de soluções de conflito como a mediação visam diminuir ou desafogar a carga de processos no Poder Judiciário, contemplando a aproximação 
das partes, para uma resolução de conflitos, de forma amigável, através de uma conversa, com ideias criativas e com ganhos mútuos, mantendo 0 bom relacionamento entre elas e objetivando uma solução definitiva.

\section{AUDIÊNCIA REALIZADA POR CONCILIADOR OU MEDIADOR, E DA PARTICIPAÇÃO DO JUIZ COMO JULGADOR}

A Mediação no Código de Processo Civil tem como características principal, propiciar a tomada de decisões pelas partes envolvidas em uma determinada controvérsia, no qual uma terceira pessoa, que não sofre os efeitos do pré-julgamento, imparcial, dá assistência às pessoas em conflito, com a finalidade de que possam manter uma comunicação produtiva à procura de um acordo possível entre elas, que vem de encontro à demanda da sociedade pela valorização do direito, da cidadania e do bem estar social.

O conciliador e o mediador são figuras que ganham importância no CPC/2015, recebendo atenção especial dos artigos 165 a 175.

Emerge dos $\S \S 2^{\circ}$ e $3^{\circ}$ do artigo 165 do código de processo civil, mudança de paradigma do código para a condição de instrumentos da promoção da pacificação (CF/88), e distingue o conciliador e o mediador.

$\S 2^{\circ} \mathrm{O}$ conciliador, que atuará preferencialmente nos casos em que não houver vínculo anterior entre as partes, poderá sugerir soluções para o litígio, sendo vedada a utilização de qualquer tipo de constrangimento ou intimidação para que as partes conciliem.

$\S 3^{\circ}$ O mediador, que atuará preferencialmente nos casos em que houver vínculo anterior entre as partes, auxiliará aos interessados a compreender as questões e os interesses em conflito, de modo que eles possam, pelo restabelecimento da comunicação, identificar, por si próprios, soluções consensuais que gerem benefícios mútuos (BRASIL, 2015).

Estabelece-se uma distinção importante entre o conciliador e o mediador, separandose pelo tipo de conflito, qual seja, o vínculo existente entre as partes. Nas relações jurídicas duradouras e permanentes, caracteriza-se a mediação, já nas relações 
jurídicas descontinuada o mais indicado para a solução do conflito como dispõe o código, é a conciliação.

Bem ponderou Kazuo Watanabe dizendo observar na prática, que alguns conflitos, principalmente aqueles que acontecem entre duas pessoas que possuem um contato direto constante (o marido e a esposa, dois vizinhos, pessoas residentes no mesmo condomínio), exigem uma técnica de solução, tal como a mediação, pela razão de se buscar nesses conflitos não só a pacificação dos conflitantes, mas a solução do conflito, visto que a técnica de hoje de solução pelo juiz, por meio da sentença, é uma mera técnica de solução de conflitos, e não uma técnica de pacificação dos conflitos.

Caso as partes não sejam pacificadas, se não compreenderem a necessidade da busca por uma solução de convivência, ou seja, se a técnica não for à da pacificação das partes, mas sim a da solução dos conflitos, as mesmas partes retornarão ao tribunal outras vezes. Então, existe diferença no tratamento dos conflitos entre duas pessoas em contato permanente e entre pessoas que não se conhecem.

Em uma batida de carro, por exemplo, geralmente, o problema é resolvido pelo pagamento de uma indenização; assim, nessa conjectura, o problema é resolvido pela solução do conflito, no entanto, em outras, nas quais as partes necessitam de uma convivência futura, continuada, há muito mais a necessidade de pacificação do que de solução de conflito. (DELGADO, 2003)

Como se pode notar, o papel do conciliador na audiência de conciliação consiste em orientar e apontar soluções na tentativa de agilizar a prestação jurisdicional, sem qualquer tipo de constrangimento ou intimidação, para que as partes envolvidas no conflito resolvam o conflito. E o mediador, por outro lado, atua como facilitador do diálogo entre as partes, para que as mesmas possam chegar à melhor solução para o problema, sem interferir em suas decisões, apenas propiciando que conversem sobre o problema e que reconheçam os sentimentos latentes, para a tomada de decisão por si própria. 
Os poderes, os deveres e a responsabilidade do juiz é um dos temas mais discutidos na comunidade jurídica, isso porque o juiz é o principal sujeito do processo, incumbido de conduzir o processo e de velar para que todos os participantes do processo tenham um comportamento condizente com a tradição forense. $O$ juiz é o que decide as questões trazidas pelas partes para solução perante o Poder Judiciário. O CPC/2015, imprime uma mudança nessa relação jurídica processual, com esteio no princípio da cooperação, da qual todos participantes, devem cooperar entre si, buscando-se, com isso, um processo mais equilibrado e com partes mais participativas. Essa mudança emerge de superação de preconceitos.

O CPC atribui ao magistrado o dever de pacificar os conflitos na obtenção da solução consensual das controvérsias, isto porque o sistema prevê que a solução da sentença de procedência e improcedência, resolve o processo, mas não termina com o conflito, em razão disso o art. $3^{\circ}$, $\S \S 2^{\circ}$ e $4^{\circ}$ do código em comento, encerra os princípios fundamentais do processo civil, fomentando que todos os profissionais devem promover a solução consensual, inclusive o Juiz, devendo estimular a conciliação e a mediação para a solução conflituosa por meio da composição amigável.

Traz a lume o art. 139, V, do CPC/2015:

O juiz dirigirá o processo conforme disposições deste Código, incumbindo-Ihe:

$\mathrm{V}$ - Promover, a qualquer tempo, a autocomposição ${ }_{1}$ preferencialmente com o auxílio de conciliadores e mediadores judiciais (BRASIL, 2015).

$\mathrm{Na}$ análise, o código de processo civil não veda a participação do juiz na audiência de conciliação ou mediação na composição, que se serve do estímulo do juiz onde as partes firmam, em negociação direta, a transação, que o próprio homologa, juntamente com o auxílio de conciliadores e mediadores.

Segundo Scarpinella,

ao mesmo tempo em que o Código concede toda essa organização vocacionada a potencializar a utilização de métodos de solução de conflitos, ele também atribui ao juiz a incumbência de promover a 
autocomposição a qualquer tempo, preferencialmente com o auxílio de conciliadores e de mediadores (BUENO, 2017, p. 220).

Pode-se, assim, afirmar, que a Mediação no Código de Processo Civil tem como características principal propiciar a tomada de decisões pelas partes envolvidas em uma determinada controvérsia continua, no qual uma terceira pessoa, que não sofre os efeitos do pré-julgamento, imparcial, fornece assistência às pessoas em conflito, a fim de que possam manter uma comunicação produtiva à procura de um acordo possível entre elas, que vem de encontro à demanda da sociedade pela valorização do direito, da cidadania e do bem estar social.

Neste contexto, se justifica a mediação que está permeada em vários dispositivos do Código de Processo Civil, possibilitando que as pessoas envolvidas em conflitos encontrem uma solução mais rápida para seus problemas quando instaurado o processo judicial, e com isso, realmente, obtenha as mudanças de paradigmas de uma justiça transformadora e moderna.

\section{AS RESPONSABILIDADES DO CONCILIADOR NA MEDIAÇÃO PREVIDENCIÁRIA}

As responsabilidades do conciliador na mediação previdenciária, parte do princípio em que os mesmos devem tratar com isonomia os administrados e segurados, sendo envolvidos como parte no processo a Administração Pública e os órgãos previdenciários.

Neste sentido, temos que nas ações previdenciárias, à concessão de benefícios previdenciários pleiteados no âmbito judicial Federal, o órgão previdenciário não pode deixar de reconhecer um benefício pleiteado de um segurado e deixar de reconhecer o mesmo tipo de benefício a outro segurado, o qual tem por situação objetivamente idêntica. Assim, neste sentido, temos a isonomia que constitui uma limitação à discricionariedade na realização dos acordos celebrados com a liberdade entre as partes. 
Dando assim, um resultado de um direito aos demais administrados em mesmo acordo. Sob outra perspectiva, se a situação jurídica é completamente idêntica, a Administração deve considerar a mesma solução para todos os casos, visto que a isonomia é imposta sobre situações semelhantes. Tenha-se, por exemplo, a situação em que o número de variáveis objetivas é menor, como a apuração do direito voltado a um benefício previdenciário, sendo mais fácil identificar a similaridade dos casos. (SOUZA, 2012).

\section{CONSIDERAÇÕES FINAIS}

Conforme o artigo apresentado, chegamos à conclusão através das pesquisas nas legislações específicas e suas inovações no sistema processual que trouxeram vários meios consensuais para o centro do cenário de solução de conflitos.

Podendo observar que as sessões consensuais vêm aumentando de forma intensa na trilha processual, alterando significativamente a figura do terceiro imparcial que é destacado pela realização de mediação ou conciliação como um auxiliar da justiça para a composição de diversos litígios, bem como na diminuição da demanda e agilidade processual aplicada pelo poder judiciário.

Demonstrando, assim, através da pesquisa, que o conciliador atua para zelar pela isonomia e pela decisão informada ao segurado em realizar ou não eventual acordo, o qual possui total liberdade no acordo entre as partes, sendo apenas orientado da situação discutida no processo, sem interferência do conciliador.

Sendo ainda, observado nas pesquisas em relação às ações previdenciárias, que a parte autora tende a concordar com a proposta do ente federativo, ou seja, a autarquia, uma vez que a não aceitação da proposta lhe imposta lhe acarretará grandes transtornos, tanto emocional quanto financeiro, visto que o processo irá se estender sem limite de tempo vindo a onerar ainda mais seu andamento do processo, na qual fica o mesmo quase obrigado a aceitar a proposta para não incorrer na morosidade do tempo. 
Deste modo, entendemos que seria necessário e urgente uma melhor preparação e estruturação da parte administrativa do Instituto Nacional de Seguro Social - INSS, em virtude da grande demanda que a autarquia está sujeita e, ainda, em relação à morosidade dos processos. Sendo possível uma melhor organização da autarquia, para que o segurado possa ter ciência de seus direitos e, através dele, desfrutar do tão sonhado benefício.

E neste entendimento com a conciliação e o acordo entre as partes, vemos que, ainda que o benefício seja menor, o tempo de espera pela efetividade do provimento jurisdicional é longo demais, assim como se estimulando a conciliação, viabiliza-se de certa forma a economia financeira em face do Instituto Nacional do Seguro Social INSS, em virtude das condições para a realização de acordo. Podendo também concluir que o Procurador da autarquia somente participa da conciliação caso tenha certeza de que a parte autora tem direito ao benefício pleiteado, caso contrário, se não concorda com a conciliação, enseja assim, um acordo baseado em concessões recíprocas.

Por fim, chegamos à conclusão de que a homologação entre as partes é vista com bons olhos ao poder judiciário, considerando a vontade das partes, o que contribui para desafogar a demanda judicial, e a composição do litígio, deixando a desejar o direito constitucional do segurado que acaba renunciando o valor maior ante a demora na finalização do processo, vindo de uma certa forma a beneficiar a autarquia.

\section{REFERÊNCIAS BIBLIOGRÁFICAS}

Anuário da Justiça Brasil, 2017, ainda há Juízes no Brasil, consultor jurídico.

ALVIN, Angélica Arruda et. al. Comentários ao código de processo civil. Coordenação de- 2 ed. São Paulo: Saraiva, 2017

BRASIL. Código de Processo Civil. 2015. 
BRASIL. Lei no 13.140, de 26 de junho de 2015, Disponível em: http://www.planalto.gov.br/ccivil_03/_Ato2015-2018/2015/Lei/L13140.htm , Acesso em 30-06-2020.

BRASIL. Lei no 12.154, de 23 de dezembro de 2009. Disponível em: http://www.planalto.gov.br/ccivil_03/_Ato2007-2010/2009/Lei/L12154.htm, Acesso em 30-06-2020

BRASIL. Resolução № 125 de 29/11/2010, Disponível em: https://atos.cnj.jus.br/atos/detalhar/atos-normativos?documento=156, Acesso em 3006-2020.

BUENO, C. S. Comentário ao código de processo civil. São Paulo: Saraiva. Vol. 1. 2017.

CABRAL, V. G.; POSSAS FILHO, W. de C. Conciliação e efetividade dos direitos previdenciários no Brasil: paradoxos da atuação judicial do INSS. In: Acesso à justiça I. Organização CONPEDI/UFPB. Florianópolis: CONPEDI, 2014.

DELGADO, José et. al. Mediação: Um projeto inovador. Brasília: Centro de Estudos Judiciários, Conselho da Justiça Federal, CEJ, 2003, pg 56

MEDEIROS NETO, E. M. et. al. Audiência de tentativa de conciliação ou mediação obrigatória? Disponível em: https://www.paulistanomediacao.com.br/copia-jthomologa-acordo-feito-por- Site Disponível em: http://www.in.gov.br/materia//asset_publisher/Kujrw0TZC2Mb/content/id/22795910/do1-2016-05-06-resolucao-n397-de-4-de-maio-de-2016-22795874, Acesso em 29/06/2020.

SOUZA, L. M. de. Meios consensuais de solução de conflitos envolvendo entes públicos: negociação, mediação e conciliação na esfera administrativa e judicial. Belo Horizonte: Fórum, 2012.

VASCONCELOS, C. E. de. Mediação de conflitos e práticas restaurativas. 5e ed. Rio de Janeiro, Forence, São Paulo: Método, 2017. 


\section{APÊNDICE - REFERÊNCIAS DE NOTA DE RODAPÉ}

5. Nós, representantes do povo brasileiro, reunidos em Assembléia Nacional Constituinte para instituir um Estado Democrático, destinado a assegurar o exercício dos direitos sociais e individuais, a liberdade, a segurança, o bem-estar, o desenvolvimento, a igualdade e a justiça como valores supremos de uma sociedade fraterna, pluralista e sem preconceitos, fundada na harmonia social e comprometida, na ordem interna e internacional, com a solução pacífica das controvérsias, promulgamos, sob a proteção de Deus, a seguinte Constituição da República Federativa do Brasil

6. Comentários ao código de processo civil/coordenação de Angélica Arruda Alvin...[ et. al.] - 2 ed. São Paulo: Saraiva, 2017

7. Anuário da Justiça Brasil 2017, ainda há Juízes no Brasil, consultor jurídico, pg.160

8.

Disponível

em:

http://www.in.gov.br/materia//asset_publisher/Kujrw0TZC2Mb/content/id/22795910/do1-2016-05-06-resolucao-n397-de-4-de-maio-de-2016-22795874, Acesso em 29/06/2020.

Enviado: Dezembro, 2020.

Aprovado: Dezembro, 2020. 